\title{
Potensi Karbon pada Lamun Thalassia hemprichii dan Enhalus acoroides di Perairan Pantai Waai Pulau Ambon
}

\author{
Carbon Potential on Seagrass Thalassia hemprichii and Enhalus acoroides in Waai \\ Coastal Waters Ambon Island
}

\author{
Charlotha Irenny Tupan ${ }^{1}$, Ferdinandus Sangur ${ }^{2}$, Grasiano W Lailossa ${ }^{2}$ \\ ${ }^{1}$ Jurusan Manajemen Sumberdaya Perairan, Fakultas Perikanan dan Ilmu Kelautan, Universitas \\ Pattimura, Ambon, 97233, Indonesia \\ ${ }^{2}$ Jurusan Teknika, Akademi Maritim Maluku, Ambon, 97116, Indonesia \\ *Korespondensi: lotjetupan@gmail.com
}

\begin{abstract}
ABSTRAK
Lamun sebagai tanaman tingkat tinggi memanfaatkan karbondioksida untuk menghasilkan bahan organik dan menyimpannya dalam biomassa, sehingga tanaman ini berpotensi mengurangi pencemaran gas karbondioksida di lingkungan. Penelitian ini bertujuan untuk menganalisis cadangan dan serapan karbon dua spesies lamun di Perairan Pantai Waai, Pulau Ambon. Dua spesies lamun yang menjadi fokus penelitian adalah Thalassia hemprichii dan Enhalus acoroides yang merupakan spesies dominan pada perairan tersebut. Penelitian ini dilakukan pada bulan Juni 2019 pada dua stasiun penelitian berdasarkan perbedaan substrat yaitu Stasiun 1 mewakili substrat berlumpur, dan Stasiun 2 mewakili substrat berpasir. Analisis cadangan karbon dilakukan dengan menggunakan pendekatan analisis biomassa, yang dibedakan atas bagian di atas substrat dan bagian di bawah substrat. Analisis serapan karbon dilakukan dengan menggunakan pendekatan analisis laju produksi. Analisis kandungan karbon didasarkan pada metode Walkley and Black. Berdasarkan hasil penelitian diperoleh potensi cadangan karbon pada spesies $E$. acoroides berkisar antara 112,38 - 126,34 gC. $\mathrm{m}^{-2}$ dan lebih tinggi dari pada T. hemprichii yang berkisar antara 9,31 - 11,28 gC.m ${ }^{-2}$. Cadangan karbon ini lebih tinggi pada bagian bawah substrat khususnya pada bagian rhizoma yang mencapai 52\% dari total cadangan karbon. Potensi penyerapan karbon juga lebih tinggi pada spesies E. acoroides yang berkisar antara $1,45-1,81 \mathrm{gC} . \mathrm{m}^{-2} \mathrm{~h}^{-1}$ dibandingkan T. hemprichii yang berkisar antara 0,43 - 0,54 gC. $\mathrm{m}^{-2} \cdot \mathrm{h}^{-1}$. Kemampuan kedua spesies tersebut dalam menyerap dan menyimpan karbon lebih baik pada daerah substrat berlumpur didukung dengan kandungan nutrien yang cukup.
\end{abstract}

Kata kunci: Cadangan karbon; Enhalus acoroides; Pulau Ambon; serapan karbon; Thalassia hemprichii

\begin{abstract}
Seagrass as a high-level plant utilizes carbon dioxide to produce organic matter and stores it in biomass, so that this plant has the potential to reduce carbon dioxide pollution in the environment. This study aimed to analyze the carbon stock and carbon sequestration of two seagrass species in Waai Coastal Waters, Ambon Island. Thalassia hemprichii and Enhalus acoroides were the focus of this research. These species are the dominant species in Waai Coastal Waters. This research was conducted in June 2019 at two research stations based on substrate differences, namely Station 1 representing a muddy substrate, and Station 2 representing a sandy substrate. The analysis of carbon stocks was carried out using a biomass analysis approach, which was divided into above the substrate and below the substrate. The analysis of carbon sequestration was carried out using the production rate analysis approach. The carbon content analysis was based on the
\end{abstract}


Walkley and Black method. Based on the research results, it was found that the potential carbon stock in E. acoroides ranged from $112.38-126.34 \mathrm{gC} . \mathrm{m}^{-2}$. It was higher than $T$. hemprichii that ranged from $9.31-11.28 \mathrm{gC} . \mathrm{m}^{-2}$. This carbon stock was higher at below substrate, especially in the rhizome, which reached $50 \%$ of the total carbon stock. The potential of carbon sequestration was also higher in E. acoroides $\left(1.45-1.81 \mathrm{gC} . \mathrm{m}^{-2} \cdot \mathrm{d}^{-1}\right)$ compared to T. hemprichii $\left(0.43-0.54 \mathrm{gC} \cdot \mathrm{m}^{-2} \cdot \mathrm{d}^{-1}\right)$. The ability of these two species to absorb and store carbon was better in the muddy substrate area because of the sufficient nutrient content.

Keywords: Carbon stock; Enhalus acoroides; Ambon Island; carbon sequestration; Thalassia hemprichii

\section{PENDAHULUAN}

Ekosistem lamun merupakan salah satu ekosistem perairan, memiliki kemampuan menyerap karbon serta menyimpannya dengan karakteristik uniknya. Kemampuan ini didasarkan pada aktivitasnya melakukan proses fotosintesis yang menyerap karbondioksida dan mengubahnya menjadi karbohidrat dan menyimpannya dalam biomassa (Harris \& Feriz, 2011). Peyimpanan karbon tersebut terdistribusi pada bagian-bagian tanaman lamun seperti pada akar, rhizoma, dan daun lamun, atau dengan kata lain penyimpanan karbon terdapat pada bagian atas substrat dan bagian bawah substrat (Supriadi et al., 2014). Lagi pula kelebihan produksi karbonnya dapat disimpan di dalam sedimen dalam kurun waktu yang lama seperti yang ditunjukan oleh spesies Posidonia oceanica (Mateo et al., 2003). Padang lamun mengubur karbon dengan kecepatan 35 kali lebih cepat dari hutan hujan tropis, dan sedimennya tidak menjadi jenuh (McLeod et al., 2011). Padang lamun juga dapat mengikat karbon selama ribuan tahun dibandingkan hutan darat yang mengikat karbon selama beberapa dekade (Macreadie et al., 2014). Selain tersimpan pada bagian bawah substrat biomassa lamun juga akan masuk dalam jaring makanan melalui proses makan memakan oleh herbivora yang dilanjutkan dengan pemangsaan pada tingkat trofik lebih tinggi maupun melalui proses dekomposisi serasah.

Komunitas lamun tersebar pada beberapa perairan di Pulau Ambon, salah satu adalah Perairan Pantai Negeri Waai.
Perairan ini memiliki 5 spesies lamun yaitu, Enhalus acoroides, Thalassia hemprichii, Cymodocea rotundata, Halodule pinifolia dan Halophila ovalis dimana E. acoroides dan T. hemprichii merupakan spesies yang dominan (Ane, 2019). Spesies E. acoroides dan $T$. hemprichii pada umumnya mendominasi perairan Pulau Ambon selain Perairan Negeri Waai, sehingga penelitian ini difokuskan pada kedua spesies tersebut.

Penelitian tentang potensi karbon khususnya serapan karbon telah dilakukan pada spesies $E$. acoroides dan $T$. hemprichii oleh Irawan (2017), namun hasil yang diperoleh tidak maksimal karena beberapa tegakan yang diamati hilang selama penelitian. Beberapa penelitian lain juga telah dilakukan untuk mempelajari potensi karbon di lamun, namun sebagian besar difokuskan pada cadangan karbon (Indriani et al., 2017; Wawo et al., 2014; Hartati et al., 2017; Rustam et al., 2015), sedangkan penelitian ini selain meneliti cadangan karbon juga dilanjutkan dengan serapan karbon. Penelitian seperti ini telah dilakukan juga oleh Mashoreng et al., (2019) pada spesies $T$. hemprichii namun menggunakan metode yang berbeda dengan penelitian ini.

Terkait fungsi lamun sebagai penyerap karbon, maka padang lamun perairan Waai berpotensi sebagai penyerap dan penyimpan karbon sekaligus berfungsi dalam mengurangi karbon dioksida di perairan maupun di atmosfir. Penelitian ini bertujuan untuk mengetahui potensi cadangan karbon dan penyerapan karbon pada spesies lamun $T$. hemprichii dan E. acoroides. 


\section{METODE PENELITIAN}

\section{Stasiun Penelitian}

Penelitian ini dilakukan pada bulan Juni 2019 pada 2 stasiun penelitian berdasarkan perbedaan substrat yaitu Stasiun 1 mewakili substrat berlumpur, dan Stasiun 2 mewakili substrat berpasir di Perairan Pantai Negeri Waai, Pulau Ambon (Gambar 1).

\section{Pengambilan Sampel dan Analisis Cadangan Karbon}

Analisis cadangan karbon dimulai dengan perhitungan kerapatan dan biomassa lamun (Irawan, 2017). Pengambilan sampel lamun untuk menghitung kerapatan dan biomassa menggunakan kuadrat pengamatan ukuran 1 x $1 \mathrm{~m}$ dengan pengulangan sebanyak 3 kali untuk masing-masing spesies (T. hemprichii dan E. acoroides) dan masing masing stasiun. Sampel lamun diambil sebanyak 10 tegakan yang utuh kemudian dipisahkan antara akar, rhizoma dan daun dan dikeringkan pada suhu $105^{\circ}$ C selama 14 jam sampai mencapai berat konstan. Perhitungan biomassa dipisahkan antara bagian atas substrat meliputi daun dan selundang dan bagian di bawah substrat meliputi akar dan rhizoma (Rustam et al., 2019) Analisis kandungan karbon dilakukan pada Laboratorium Departemen Ilmu Tanah dan Sumberdaya Lahan, Fakultas Pertanian, IPB yang didasarkan pada metode Walkley \& Black (Schumacher, 2002). Kerapatan spesies lamun dihitung sebagai jumlah tegakan dari masingmasing spesies per satuan luas (teg. $\mathrm{m}^{-2}$ ), dan biomassa per satuan luas dihitung dari jumlah kerapatan dikali berat kering per tegakan $\left(\right.$ gbk. $\left.\mathrm{m}^{-2}\right)$. Cadangan karbon atau biomassa karbon diperoleh dari berat kering lamun dibagi luas area pengamatan dikali kandungan karbon dengan satuan gC. $\mathrm{m}^{-2}$ (Howard et al., 2014).

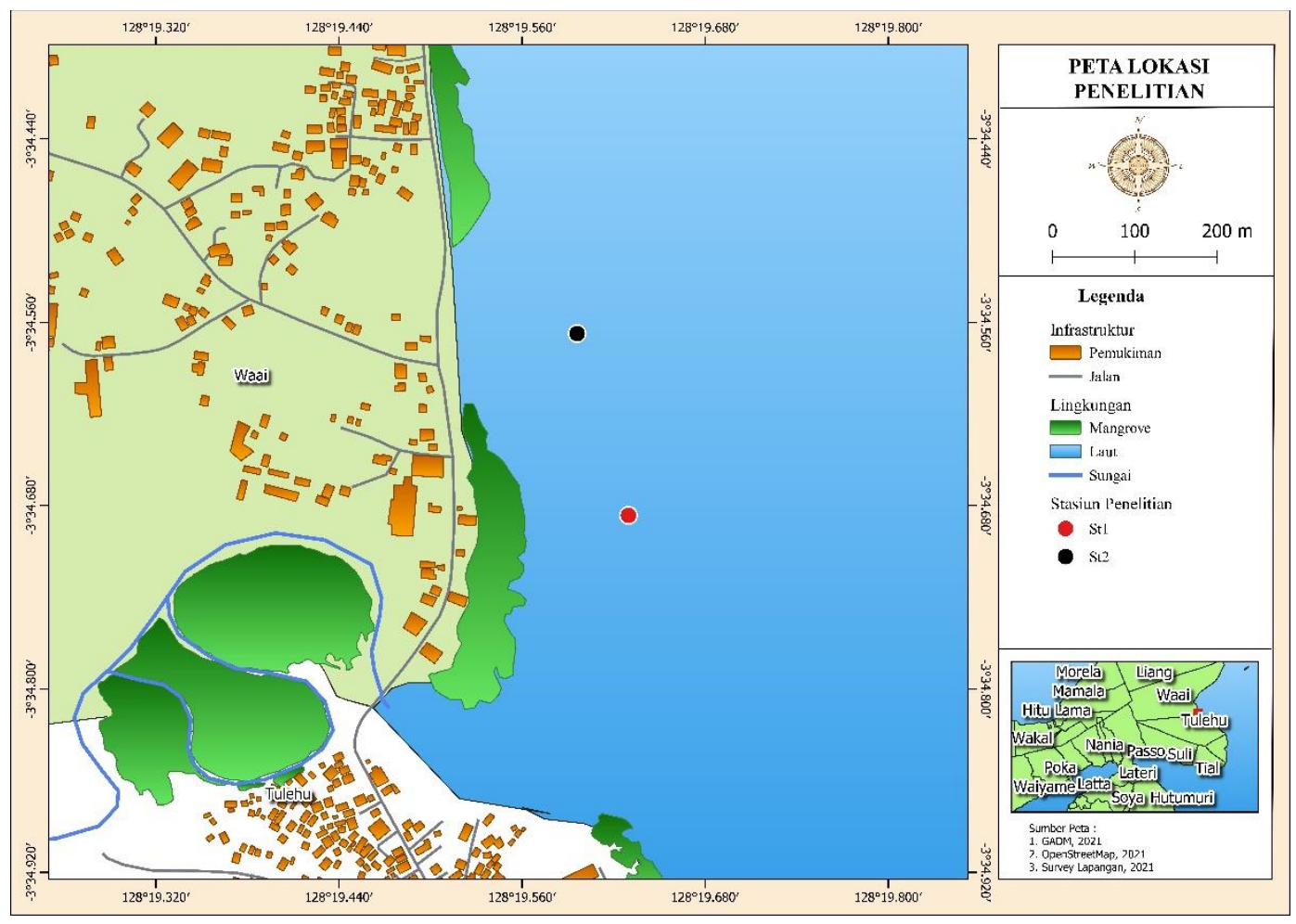

Gambar 1. Peta Lokasi Penelitian 


\section{Serapan karbon}

Pengukuran laju produksi sebagai hasil konversi karbon dalam proses fotosintesis dilakukan untuk mengetahui serapan karbon lamun. Pengukuran laju produksi dimulai dengan pengukuran pertumbuhan lamun ( $T$. hemprichii dan $E$. acoroides) pada masing-masing stasiun. Pertumbuhan lamun diukur pada daun sebanyak 20 tegakan selama 10 hari dengan menggunkan metode penandaan (Short \& Duarte, 2001) yang dimodifikasi. Modifikasi yang dilakukan adalah pada prosedur penandaan dilengkapi dengan penggunaan benang dan patok sebagai penyanggah.

Daun lamun pada tiap tegakan diberi tanda dengan membuat lubang dan dimasukan benang berwarna putih pada ketinggian $1 \mathrm{~cm}$ (spesies $T$. hemprichii) dan $2 \mathrm{~cm}$ (spesies E. acoroides) dari pangkal daun. Selanjutnya dipasang patok (tusuk sate) dimana ujung patok berada tepat pada tanda lubang yang telah diberi benang. Setelah 10 hari, tepat pada bagian daun yang sejajar dengan ujung patok, diberi tanda kemudian dipotong. Bagian antara daun yang dipotong dan tanda benang penanda merupakan daun yang tumbuh, selanjutnya diukur panjangnya. Daun-daun tersebut kemudian dimasukan ke dalam plastik sampel dan diberi label. Di laboratorium, daun dikeringkan pada suhu $105^{\circ} \mathrm{C}$ selama 14 jam sampai mencapai berat konstan, dan dianalisis biomassanya. Analisis kandungan karbon dilakukan pada Laboratorium Departemen Ilmu Tanah dan Sumberdaya Lahan, Fakultas Pertanian, IPB yang didasarkan pada metode Walkley \& Black (Schumacher, 2002). Pertumbuhan dihitung sebagai pertambahan panjang daun selama waktu pengamatan $\left(\mathrm{cm} . \mathrm{h}^{-2}\right)$ dan produksi diperoleh dari produksi satu tegakan dikali dengan kerapatan (gbk.m$\left.{ }^{2} \cdot \mathrm{h}^{-1}\right)$. Pengukuran pertumbuhan $\left(\mathrm{cm} \cdot \mathrm{h}^{-1}\right)$ dan produksi daun lamun $\left(\mathrm{gbk} \cdot \mathrm{m}^{-2} \cdot \mathrm{h}^{-1}\right)$ kemudian dikonversi dengan \%C per bobot kering menjadi $\mathrm{gC} \cdot \mathrm{m}^{-2} \cdot \mathrm{h}^{-1}$ (Rustam et al., 2019)

\section{HASIL DAN PEMBAHASAN}

\section{Cadangan Karbon}

Berdasarkan hasil analisis kerapatan lamun di Perairan Negeri Waai, diperoleh E. acoroides lebih tinggi dibandingkan $T$. hemprichii pada ke 2 stasiun (Tabel 1). Spesies ini tumbuh mendominasi perairan yang lebih dalam dengan substrat berlumpur. Lamun $E$ acoroides umumnya banyak ditemukan di bawah air surut rata-rata pada dasar pasir berlumpur, mereka tumbuh subur pada daerah yang terlindung di pinggir bawah dari mintakat pasut dan di batas atas mintakat bawah litoral.

Tabel 1. Kerapatan lamun T. hemprichii dan E. acoroides

\begin{tabular}{lrr}
\hline \multirow{2}{*}{\multicolumn{1}{c}{ Spesies }} & \multicolumn{2}{c}{$\begin{array}{c}\text { Kerapatan } \\
\left.\text { (teg.m }{ }^{-2}\right)\end{array}$} \\
\cline { 2 - 3 } & St 1 & St 2 \\
\hline T. hemprichii & 92 & 79 \\
E. acoroides & 127 & 115 \\
\hline
\end{tabular}

Nilai kerapatan lamun ini sebanding dengan nilai biomassa yang dikandungnya yaitu tinggi pada spesies yang sama yaitu $E$. acoroides. Biomassa lamun merupakan fungsi dari kerapatan lamun dan ukuran tubuh dari lamun tersebut yang tumbuh pada suatu daerah tertentu (Hartati et al., 2017). Dengan demikian maka E. acoroides yang memiliki kerapatan dan ukuran tubuh yang besar secara otomatis memiliki biomassa yang besar pula. Biomassa pada spesies $E$ acoroides ini sebagain besar terdapat pada bagian rhizoma atau pada bagian di bawah substrat (Tabel 2). Secara morfologi bagian rhizoma dari $E$. acoroides yang ditemukan memiliki ukuran yang lebih besar dengan diameter mencapai $1 \mathrm{~cm}$. Hal ini berbeda dengan spesies T. hemprichii yang memiliki biomassa lebih tinggi pada daun dibandingkan akar dan rhizoma. Daun $T$. hemprichii ditemukan memiliki panjang mencapai $15 \mathrm{~cm}$. 
Tabel 2. Biomassa Lamun T. hemprichii dan E. avoroides

\begin{tabular}{ccrrrr}
\hline \multirow{2}{*}{ Stasiun } & \multirow{2}{*}{ Spesies } & Daun & Rhizoma & Akar & Total \\
\cline { 3 - 6 } & & & & & \\
\hline \multirow{2}{*}{1} & T. hemprichii & 11,96 & 9,20 & 4,60 & 25,76 \\
& E. acoroides & 82,55 & 127,00 & 63,50 & 273,05 \\
\hline \multirow{2}{*}{2} & T. hemprichii & 10,27 & 7,90 & 3,95 & 22,12 \\
& E. acoroides & 74,75 & 115,00 & 57,50 & 247,25 \\
\hline
\end{tabular}

Perhitungan biomasa dalam satuan gram karbon per meter persegi $\left(\mathrm{gC} . \mathrm{m}^{-2}\right)$ atau dikenal dengan cadangan karbon yaitu dengan menghitung bobot karbon biomasa per $\mathrm{m}^{2}$ bagian tanaman lamun dari gram bobot kering $\left(\right.$ gbk. $\left.\mathrm{m}^{-2}\right)$ yang dikonversi ke mol $\mathrm{C}$ dengan persentase kandungan karbon (\% C) bobot kering biomasa (Howard et al., 2014). Dengan demikian maka hasil perhitungan cadangan karbon pada padang lamun $T$. hemprichii dan E. acoroides adalah seperti pada Tabel 3.

Nilai cadangan karbon tertinggi terdapat pada spesies E. acoroides $\left(112,38\right.$ - 126,34 gC. $\left.\mathrm{m}^{-2}\right)$, dan terutama pada bagian rhizoma atau bagian bawah substrat $\left(59,11-66,12\right.$ gC.m $\left.{ }^{-2}\right)$. Hal ini disebabkan karena rhizoma pada $E$ acoroides merupakan bagian yang lebih besar dari pada organ lamun yang lain. Lamun yang memiliki ukuran morfologi tubuh yang besar cenderung mengembangkan biomassa lebih besar pada bagian bawah substrat, oleh karena itu mempunyai kapasitas mengakumulasi karbon yang lebih tinggi (Supriadi et al., 2014). Selain itu karbon pada bagian bawah substrat merupakan tempat penyimpanan hasil fotosintesis yang akan mendukung pertumbuhan lamun jika proses fotosintesis tidak berjalan secara optimal (Alcoverro et al., 2001). Selanjutnya menurut Fourqurean et al., (2012) bahwa karbon organik secara global disimpan dalam biomassa lamun sebesar rata-rata $2,52 \pm 0,48 \mathrm{mgC} \mathrm{ha}^{-1}$ dimana dua pertiganya disimpan dalam rhizoma dan akar.

Hasil penelitian ini memperoleh nilai lebih tinggi dibandingkan hasil penelitian Irawan (2017) di Pulau Bintan yang memperoleh cadangan karbon untuk spesies E. acoroides berkisar antara $102,20-105,77$ gC.m ${ }^{-2}$. Namun demikian, nilai cadangan karbon untuk spesies T. hemprichii oleh Irawan (2017) $\left(22,83-27,46\right.$ gC.m $\left.{ }^{-2}\right)$ lebih tinggi dari hasil penelitian ini $\left(9,31-11,28 \mathrm{gC} \cdot \mathrm{m}^{-2}\right)$. Nilai cadangan karbon spesies $T$. hemprichii ini juga lebih kecil dibandingkan dengan hasil penelitian yang sama pada dua perairan lain di Pulau Ambon yaitu 50,04 - 64,75 gC. $\mathrm{m}^{-2}$ pada Perairan Tanjung Tiram, Poka (Tupan \& Wawo, 2020) dan 74,75 - 119,98 gC.m ${ }^{-2}$ pada Perairan Suli (Tupan \& Wawo, 2020).

Tabel 3. Cadangan karbon lamun T. hemprichii dan E. acoroides

\begin{tabular}{|c|c|c|c|c|c|}
\hline \multirow{2}{*}{ Stasiun } & \multirow{2}{*}{ Spesies } & \multicolumn{4}{|c|}{ Cadangan karbon $\left(\mathrm{gC} . \mathrm{m}^{-2}\right)$} \\
\hline & & Daun & Rhizoma & Akar & Total \\
\hline \multirow{2}{*}{1} & T. hemprichii & 4,83 & 4,68 & 1,77 & 11,28 \\
\hline & E. acoroides & 32,32 & 66,12 & 27,90 & 126,34 \\
\hline \multirow{3}{*}{2} & T. hemprichii & 3,96 & 3,92 & 1,43 & 9,31 \\
\hline & E. acoroides & 29,01 & 59,11 & 24,26 & 112,38 \\
\hline & & Total & & & 259,31 \\
\hline
\end{tabular}


Spesies T. hemprichii merupakan spesies yang penyebarannya luas dan dominan pada perairan Suli dan Tanjung Tiram, Poka (Sinmiassa, 2015; Tupan, 2016) dibandingkan spesies lain. Hal ini berbeda dengan Perairan Pantai Waai yang memiliki spesies yang dominan adalah E. acoroides (Rosmawati et al., 2020).

\section{Serapan Karbon}

Penyerapan karbon dalam proses fotosintesis oleh tanaman lamun berkaitan dengan aktivitas produksi dan pertumbuhan oleh tanaman tersebut. Berdasarkan hasil pengukuran pertumbuhan diperoleh rata-rata laju pertumbuhan $T$. hemprichii

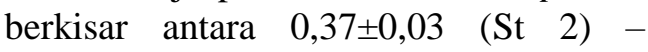
$0,40 \pm 0,03 \mathrm{~cm} \cdot \mathrm{h}^{-1}$ (St 1), dan E. acoroides berkisar antara $1,64 \pm 0,11$ (St 2) $1,71 \pm 0,11 \mathrm{~cm} \cdot \mathrm{h}^{-1}$ (St 1) (Tabel 4).

Tabel 4. Laju pertumbuhan lamun $T$. hemprichii dan E. acoroides

\begin{tabular}{lcc}
\hline \multirow{2}{*}{ Spesies } & \multicolumn{2}{c}{$\begin{array}{c}\text { Laju pertumbuhan } \\
(\mathrm{cm} / \mathrm{hr})\end{array}$} \\
\cline { 2 - 3 } & $\mathrm{St} 1$ & $\mathrm{St} 2$ \\
\hline T. hemprichii & $0,40 \pm 0,03$ & $0,37 \pm 0,03$ \\
E. acoroides & $1,71 \pm 0,11$ & $1,64 \pm 0,11$ \\
\hline
\end{tabular}

Laju pertumbuhan E. acoroides lebih cepat dibandingkan $T$. hemprichii, terkait dengan morfologi daun $E$. acoroides yang lebih lebar dan lebih panjang dari pada daun $T$. hemprichii. Perbedaan kecepatan pertumbuhan daun lamun baik terhadap jenis yang sama maupun jenis yang berbeda salah satunya dipengaruhi oleh faktor internal seperti kondisi fisiologi dan metabolisme dimana semakin luas permukaan daun maka kecepatan metabolisme semakin tinggi.
Selain itu luasnya penampang daun memungkinkan penyerapan nutrien terlarut lebih optimal (Kordi, 2011). Laju pertumbuhan E. acoroides pada penelitian ini lebih tinggi dari pada hasil penelitian Rahmawati \& Kiswara (2012) yang memperoleh nilai rata-rata pertumbuhan $1,11 \mathrm{~cm} \cdot \mathrm{h}^{-1}$ untuk jenis yang sama di Perairan Pulau Pari. Laju pertumbuhan $E$. acoroides yang tinggi ini memungkinkan nilai produktivitas dari spesies tersebut juga tinggi. Produktivitas ke dua spesies dapat dilihat pada Tabel 5.

Menurut Azkab (2000), produktivitas merupakan hasil dari produksi per satuan waktu atau merupakan kecepatan produksi. Produksi ini merupakan produksi dari daun lamun yang dapat dikategorikan sebagai laju kecepatan penyerapan karbon oleh lamun (Kiswara, 2009). Dengan demikian maka lamun $T$. hemprichii dalam 1 hari dapat menyerap karbon sebesar $0,43-0,54 \mathrm{~g}$ dalam luasan $1 \mathrm{~m}^{2}$, sedangkan $E$. acoroides dalam luasan yang sama dapat menyerap karbon sebesar 1,45 - 1,81 gr per hari. Produktivitas $T$. hemprichii pada penelitian ini lebih rendah dibandingkan hasil penelitian Tupan \& Wawo (2020) di Perairan Suli yang memperoleh hasil 1,15 - 1,51 gC. $\mathrm{m}^{-2} \mathrm{~h}^{-1}$, namun demikian memiliki nilai produktivitas E. acoroides lebih kecil dari penelitian ini $(1,42-1,62$ $\left.\mathrm{gC} \cdot \mathrm{m}^{-2} \mathrm{~h}^{-1}\right)$. Jika produktivitas lamun ke dua spesies ini dihitung untuk 1 tahun maka nilainya berkisar anatara 156,95 197,10 $\mathrm{gC}^{-\mathrm{m}^{-2} \mathrm{t}^{-1}}$ (T. hemprichii) dan $529,25-660,65 \mathrm{gC}^{-2} \mathrm{~m}^{-1}$ (E. acoroides). Nilai ini berada pada kisaran nilai produktivitas beberapa spesies lamun yang ditemukan di Pulau Pari yaitu dari 73 - $668 \mathrm{gC} \cdot \mathrm{m}^{-2} \mathrm{t}^{-1}$ (Kiswara, 2009).

Tabel 5. Produktivitas Lamun T. hemprichii dan E. acoroides

\begin{tabular}{llll}
\hline \multirow{2}{*}{ Spesies } & \multicolumn{3}{c}{ Produktivitas $\left(\mathrm{gC} \cdot \mathrm{m}^{-2} \cdot \mathrm{h}^{-1}\right)$} \\
\cline { 2 - 4 } & $\mathrm{St} 1$ & $\mathrm{St} \mathrm{2}$ & Total \\
\hline T. hemprichii & 0,54 & 0,43 & 0,97 \\
E. acoroides & 1,81 & 1,45 & 3,26 \\
Total & 2,35 & 1,88 & 4,23 \\
\hline
\end{tabular}


Perbedaan nilai produktivitas dapat dipengaruhi oleh musim dan faktor-faktor kualitas perairan yang mempengaruhi pertumbuhan dari jenis-jenis lamun tersebut. Pertumbuhan dan produktivitas yang tinggi berada pada stasiun 1 dengan substrat dasar perairan adalah lumpur dibandingkan stasiun 2 dengan substrat pasir. Ketersediaan unsur hara $\mathrm{N}$ dan $\mathrm{P}$ lebih tinggi pada substrat dengan ukuran butiran sedimen yang lebih kecil, sehingga akan mempengaruhi tingginya pertumbuhan lamun (Febriyantoro et al., 2016). Hal ini sejalan dengan hasil analisis kandungan fosfat dan nitrat pada sedimen dengan nilai fosfat berkisar antara 0,02 (St 2) - 0,03 ppm (St 1) dan nitrat berkisar antara 0,01 (St 2) - 0,06 ppm (St 1).

\section{KESIMPULAN}

Lamun T. hemprichii dan E. acoroides yang tumbuh pada substrat berpasir dan berlumpur pada Perairan Pantai Waai menghasilkan total cadangan karbon sebesar 259,32 gC. $\mathrm{m}^{-2}$ dan menyerap karbon sebesar 4,23 gC. $\mathrm{m}^{-2} \cdot \mathrm{h}^{-1}$. Kemampuan menyimpan dan menyerap karbon lebih tinggi terdapat pada spesies E. acoroides yang tumbuh pada substrat berlumpur

\section{UCAPAN TERIMA KASIH}

Penulis mengucapkan terima kasih kepada Direktorat Jenderal Penguatan Riset dan Pengembangan, Kementerian Riset, Tekhnologi dan Pendidikn Tinggi, Republik Indonesia yang mendanai penelitian ini melalui skema Penelitian Dasar, Kompetitif Nasional.

\section{DAFTAR PUSTAKA}

Alcoverro, T., Manzanera, M., \& Romero, J. (2001). Annual metabolic carbon balance of the seagrass Posidonia oceanica: the importance of carbohydrate reserves. Marine Ecology Progress Series, 211, 105116.

Ane, D. W. (2019). Kandungan Logam Berat Timbal $(\mathrm{Pb})$ Pada Lamun
Enhalus acoroides Sebagai Dasar Pengelolaan di Perairan Pantai Waai, Kabupaten Maluku Tengah. Fakultas Perikanan dan Ilmu Kelautan, UNPATTI.

Azkab, M. H. (2000). Produktivitas Dilamun. Oseana, $X X V(1), 1-11$.

Febriyantoro, D., Tanjung, A., \& Nurrachmi, I. (2016). Biomassa dan Kerapatan Lamun Berdasarkan Rasio N: P pada Sedimen di Perairan Pantai Trikora Kabupaten Bintan Provinsi Kepulauan Riau. Riau University.

Fourqurean, J. W., Duarte, C. M., Kennedy, H., Marbà, N., Holmer, M., Mateo, M. A., Apostolaki, E. T., Kendrick, G. A., Krause-Jensen, D., \& McGlathery, K. J. (2012). Seagrass ecosystems as a globally significant carbon stock. Nature Geoscience, 5(7), 505-509.

Harris, J. M., \& Feriz, M. B. (2011). Forests, Agriculture, and Climate: Economics and Policy Issues. https://doi.org/10.1111/j.19391676.2008.0203.x

Hartati, R., Pratikto, I., \& Pratiwi, T. N. (2017). Biomassa dan Estimasi Simpanan Karbon pada Ekosistem Padang Lamun di Pulau Menjangan Kecil dan Pulau Sintok, Kepulauan Karimunjawa. Buletin Oseanografi Marina, 6(1), 74. https://doi.org/10.14710/buloma.v6i 1.15746

Howard, J., Hoyt, S., Isensee, K., Telszewski, M., \& Pidgeon, E. (2014). Coastal blue carbon: methods for assessing carbon stocks and emissions factors in mangroves, tidal salt marshes, and seagrasses.

Indriani, Wahyudi, A. J., \& Yona, D. (2017). Cadangan Karbon di Area Padang Lamun Pesisir Pulau Bintan , Kepulauan Riau Carbon Stock in Seagrass Meadows of Bintan Island , Riau Archipelago Abstrak Pendahuluan Metodologi. Oseanologi Dan Limnologi Di Indonesia, 2(3), 1-11.

Irawan, A. (2017). Potensi Cadangan dan Serapan Karbon oleh Padang Lamun 
di Bagian Utara dan Timur Pulau Bintan. Oseanologi Dan Limnologi Di Indonesia, 2(3), 35-48.

Kiswara, W. (2009). Studi Pendahuluan: Potensi Padang Lamun Sebagai Karbon Rosot dan Penyerapan Karbon di Pulau Pari, Teluk Jakarta.

http://file.pksdmo.lipi.go.id/id0185fee0-2650_215.pdf

Kordi, M. G. H. (2011). Ekosistem Lamun (seagrass); fungsi, potensi dan pengelolaan. Rineka Cipta. Jakarta, 170.

Macreadie, P. I., Baird, M. E., TrevathanTackett, S. M., Larkum, A. W. D., \& Ralph, P. J. (2014). Quantifying and modelling the carbon sequestration capacity of seagrass meadows-a critical assessment. Marine Pollution Bulletin, 83(2), 430-439.

Mashoreng, S., Alprianti, S., Samad, W., Isyrini, R., \& Inaku, D. F. (2019). Serapan Karbon Lamun Thalassia hemprichii Pada Beberapa Kedalaman. Jurnal Ilmu Kelautan Spermonde, 5(1), 11-17. https://doi.org/10.20956/jiks.v5i1.7 031

Mateo, M.-Á., Sánchez-Lizaso, J.-L., \& Romero, J. (2003). Posidonia oceanica 'banquettes': a preliminary assessment of the relevance for meadow carbon and nutrients budget. Estuarine, Coastal and Shelf Science, 56(1), 85-90.

McLeod, E., Chmura, G. L., Bouillon, S., Salm, R., Björk, M., Duarte, C. M., Lovelock, C. E., Schlesinger, W. H., \& Silliman, B. R. (2011). A blueprint for blue carbon: Toward an improved understanding of the role of vegetated coastal habitats in sequestering $\mathrm{CO} 2$. Frontiers in Ecology and the Environment, 9(10), 552-560. https://doi.org/10.1890/110004

Rahmawati, S., \& Kiswara, W. (2012). Cadangan Karbon dan Kemampuan Sebagai Penyimpan Karbon pada Vegetasi Tunggal Enhalus acoroides di Pulau Pari, Jakarta. Oseanologi Dan Limnologi Di Indonesia, 38(1),
143-150.

Rosmawati, T., Huliselan, N. V, Khouw, A. S., \& Tupan, C. I. (2020). Laju Pertumbuhan Lamun Enhalus acoroides yang Di Transplantasi dengan Menggunakan Metode Terfs Di Perairan Pantai Desa Waai Kabupaten Maluku Tengah. BIOSEL (Biology Science and Education): Jurnal Penelitian Science Dan Pendidikan, 9(1), 6980.

Rustam, A, Adi, N. S., Daulat, A., Kiswara, W., Yusup, D. S., \& Rappe, R. A. (2019). Pedoman pengukuran karbon di ekosistem padang lamun. ITB Press. Bandung.

Rustam, Agustin, Kepel, T. L., Afiati, R. N., Salim, H. L., -, M. A., -, A. D., Mangindaan, P., Sudirman, N., Puspitaningsih, Y., Dwiyanti, D., \& Hutahaean, A. (2015). Peran Ekosistem Lamun Sebagai Blue Carbon Dalam Mitigasi Perubahan Iklim, Studi Kasus Tanjung Lesung, Banten. Jurnal Segara, 10(2). https://doi.org/10.15578/segara.v10i 2.20

Schumacher, B. A. (2002). Methods for the determination of total organic carbon (TOC) in soils and sediments.

Short, F. T., \& Duarte, C. M. (2001). Methods for the measurement of seagrass growth and production. Global Seagrass Research Methods, 2001, 155-198.

Sinmiassa, V. (2015). Status keberlanjutan komunitas lamun di perairan pesisir Negeri Suli, Kecamatan Salahutu, Kabupaten Maluku Tengah. Pascasarjana Manajemen Sumberdaya Kelautan dan Pulau Pulau Kecil, UNPATTI.

Supriadi, S., Kaswadji, R. F., Bengen, D. G., \& Hutomo, M. (2014). Carbon Stock of Seagrass Community in Barranglompo Island, Makassar (Stok Karbon pada Komunitas Lamun di Pulau Barranglompo, Makassar). ILMU KELAUTAN: Indonesian Journal of Marine Sciences, $\quad 19(1), \quad 1$. 
https://doi.org/10.14710/ik.ijms.19.

$1.1-10$

Tupan, C. I. (2016). Status Padang Lamun Perairan Tanjung Tiram, Poka, Teluk Ambon Dalam. In A. Al Ayubi (Ed.), Seminar Nasional Kelautan dan Perikanan Ke III. (pp. 94-100). Fakultas Kelautan dan Perikanan Universitas Nusa Cendana.

Tupan, C. I. Wawo, M. (2020). The potential of seagrass as a carbon stock and carbon sequestration in suli coastal waters, Ambon Island, Indonesia. Ecology, Environment and Conservation Journal, 26(2), 798-803.

Tupan, C. I., \& Wawo, M. (2020). Carbon stock of the seagrass Enhalus acoroides and Thalassia hemprichii in Tanjung Tiram coastal waters, Poka, Ambon Island. IOP Conference Series: Earth and Environmental Science, 517(1), 12008.

Wawo, M., Wardiatno, Y., Adrianto, L., \& Bengen, D. G. (2014). Carbon stored on seagrass community in marine nature tourism park of kotania bay, Western Seram, Indonesia. Jurnal Manajemen Hutan Tropika, 20(1), 51-57. https://doi.org/10.7226/jtfm.20.1.51 
